\title{
SISTEMA DE APOIO À LOCALIZAÇÃO PARA DEFICIENTES VISUAIS
}

\author{
Amilton Costa Lamas \\ Pontifícia Universidade Católica de Campinas \\ amilton@puc-campinas.edu.br \\ Rafael Isidro Souza \\ Benteler Automotive \\ rafaelisidroo@gmail.com
}

\begin{abstract}
Resumo
Desafios de localização, percepção do entorno e aquisição de produtos são uma constante na vida de deficientes visuais. Com objetivo de promover a autonomia destes desenvolveu-se, no biênio 2014-15, uma solução de Engenharia Elétrica para celulares Androide que guia o usuário, através de tecnologia Near Field Communication, até o produto de interesse e fornece a sua descrição. Este desenvolvimento foi realizado seguindo um Modelo de Desenvolvimento inspirado no IRUP e a apropriação dos resultados pelo público alvo efetuou-se aplicando parcialmente o Modelo de Apropriação de Resultados, baseado em oficinas e rodas de conversa, desenvolvido por um dos autores. A prova de conceito foi demonstrada numa instituição parceira quando os usuários e técnicos de apoio validaram o desenvolvimento. Conclui-se que soluções de Engenharia Elétrica baseadas em NFC podem ajudar os deficientes visuais a localizarem produtos de interesse, promovendo, portanto, a autonomia destes.
\end{abstract}

Palavras-chave: Engenharia Elétrica. Deficientes Visuais. Autonomia. Localização.

\section{LOCATION SUPPORT SYSTEM FOR THE VISUALLY IMPAIRED}

\begin{abstract}
Self awareness about the environment, his relative position and product acquisition are a common challenge for visually handicapped. A Near Field Communication proof of concept based on Electrical Engineering applied to Android smartphone was developed, during the 2014/2015 time period, aiming to promote the autonomy of the handicapped in locating and getting an audible description about a product of interest. The artifact development followed an IRUP inspired method and the appropriation was carried on through workshops and dialog meetings. The proof of concept was demonstrated and validated by specialized technicians and the visually impaired which approved the artifact. This extension action demonstrates that Electrical Engineering Solutions can help the visually impaired to locate and obtain information about a product, therefore promoting their autonomy.
\end{abstract}

Keywords: Electrical Engineering. Visually Impaired. Autonomy. Location.

\section{SISTEMA DE SOPORTE DE LOCALIZACIÓN PARA LOS DISCAPACITADOS VISUALES}

Resumen

Desafíos de la situación, percepción del entorno y la adquisición de productos son una constante en la vida de los discapacitados visuales. Entre 2014 e 2015, con el fin de promover la autonomía de éstos desarrolló una solución de ingeniería eléctrica para celulares Android que guía el usuario, a través de la tecnología Near Field Communication, al producto de interés y proporciona su descripción. Este desarrollo se llevó a cabo siguiendo un modelo de desarrollo basado en la apropiación de los resultados IRUP por público objetivo mediante la aplicación del modelo de apropiación de los resultados, basado en talleres y ruedas de conversación, desarrolladas por uno de los autores. La prueba de concepto fue demostrada en una institución socio cuando los usuarios y técnicos de soporte validaron el desarrollo. Se concluye que soluciones de ingeniería eléctrica basadas en NFC pueden ayudar a los discapacitados visuales para localizar productos de interés, por lo tanto, promover la autonomía de estos

Palavras clave: Ingeniería Eléctrica. Visión Deteriorada. Autonomía. Ubicación. 


\section{INTRODUÇÃO}

Globalmente estima-se que cerca de 40 a 45 milhões de pessoas são completamente cegas, 135 milhões têm baixa visão e 314 milhões tem alguma limitação visual (VELÁZQUEZ, 2010). É estimado que $87 \%$ dos cegos do mundo vivem em países em desenvolvimento, no Brasil inclusive. Segundo o censo de 2010 do IBGE (IBGE, 2010), havia no Brasil cerca de 45 milhões de pessoas com pelo menos uma deficiência representando 23,9\% da população brasileira. A deficiência visual foi a que mais incidiu sobre a população, aproximadamente 35 milhões de pessoas declararam ter dificuldade para enxergar, mesmo com o uso de óculos ou lentes de contato, o que equivale a $18,8 \%$ da população brasileira. Desse total, por volta de 6,5 milhões de pessoas apresentaram deficiência visual severa, sendo que 500 mil eram cegas $(0,3 \%$ da população) e seis milhões tinham grande dificuldade para enxergar $(3,2 \%)$.

De todas as sensações humanas aquelas recebidas pela visão são, de longe, as que mais influenciam o nosso grau de percepção. A visão, combinada com os outros sentidos, especialmente a audição e o tato, permite ter uma percepção do mundo e atuar sobre ele. Para os cegos ou deficientes visuais, a ausência de visão, total ou parcial, constitui uma barreira na execução das lidas diárias. Ter acesso à informação locomover-se e interagir com o ambiente e com outras pessoas são grandes desafios.

A comunidade científica concorda, de uma forma geral, que cegos ou deficientes visuais são mais eficientes em perceberem estímulos não visuais e que fazem melhor uso dos sentidos não visuais, especialmente a audição e o tato (LÉVESQUE, 2011). No caso de deficiência visual menos severa, estímulos luminosos são usados como ferramenta de desenvolvimento do indivíduo, auxiliando na realização de tarefas como cuidados pessoais, preparação de alimentos e controle do ambiente, bem como em atividades recreativas (BRASSAI, 2011).

Os avanços tecnológicos permitem o projeto (design) e o desenvolvimento artefatos com interfaces poderosas no apoio aos indivíduos com deficiências. Os problemas relacionados à locomoção e localização são os mais desafiadores. Eles envolvem informação espacial do entorno, definição de trajetos, orientação e desvio de obstáculos. (LÉVESQUE, 2011) (TORRE, 2009).

Apesar do notável desenvolvimento técnico-científico que resultou em equipamentos digitais sofisticados, a parcela da sociedade brasileira de baixa renda (classes D e E) e, em particular, a fração desta que possui deficiências visuais encontra não só uma escassez de artefatos ou produtos financeiramente acessíveis como também enfrenta imensas dificuldades para se apropriar destas tecnologias. Isto decorre dos desenvolvimentos não serem realizados 
considerando este público, mas também pela complexidade técnica natural envolvida no produto final. Esta situação reforça a barreira digital caminhando de encontro à inclusão social.

A percepção do entorno, identificação antecipada de objetos, localização e aquisição de produtos de interesse são ações que, se facilitadas via soluções de Engenharia Elétrica, promovem a autonomia e a cidadania de deficientes visuais. Com este objetivo desenvolveu-se uma solução para celulares androide baseada em tecnologia Near Field Communication (NFC) que, quando instalada no ambiente, guia o usuário até o produto de interesse auxiliando-o na localização, identificação das características e aquisição deste através de instruções via áudio. A aplicação desenvolvida é flexível e genérica o suficiente para ser aplicada à minimercados, livrarias, bibliotecas etc. Esta solução destina-se (público alvo) aos técnicos que trabalham na Sociedade Campineira de Atendimento ao Deficiente Visual (Pró-Visão) com sede em Campinas, SP, instituição parceira no projeto, seus assistidos e familiares. Os assistidos da Pró-Visão pertencem, em sua maioria, às classes sociais C, D e E. A expectativa do trabalho é que os técnicos e familiares dos deficientes se apropriem da tecnologia de forma a replicá-la de maneira autônoma em diferentes ambientes e situações.

\section{MATERIAIS E MÉTODOS}

O método de desenvolvimento do projeto é composto pelos pilares: 1) Gestão do Projeto; 2) Oficinas e Seminários; e 3) Desenvolvimento do Artefato. O método também emprega o Modelo de Desenvolvimento de Soluções e o Modelo de Apropriação de Resultados, a serem descritos em outra publicação.

\section{Gestão do Projeto}

Este pilar corresponde as extensas atividades iniciais do projeto, tratando da estruturação, implantação da operação. Englobando ações para garantir a mitigação de riscos durante a realização do projeto. O objetivo é garantir que o projeto atinja os objetivos propostos dentro do prazo e orçamento planejados. 
Sistema de apoio à localização para deficientes visuais

\section{Oficinas}

As oficinas se caracterizam por momentos de interação com o público alvo (técnicos que apoiam o desenvolvimento de deficientes visuais), nelas é exercitado o Modelo de Apropriação de Resultados através da troca de saberes. São espaços de contextualização tecnológica, compartilhamento de resultados e impressões, apresentação das soluções e orientações em replicação.

\section{Desenvolvimento do sistema}

O Sistema de Auxílio Visual Escutado (SAVE) desenvolvido consiste de um aplicativo (APK) para o smartphone Android e um conjunto de etiquetas baseadas em tecnologia Near Field Communication (NFC) pré-gravadas que possibilita ao deficiente visual localizar em um ambiente fechado, como um supermercado de pequeno porte, e identificar um produto de sua preferência sem o auxílio de outra pessoa. Este aplicativo NFC guia o usuário até o produto de interesse auxiliando-o na localização, identificação das características e aquisição deste através de instruções via áudio.

A arquitetura do sistema composta de um aparelho celular com sistema Androide e um conjunto de etiquetas NFC é apresentada na Figura 1 a e b, abaixo.


(a)

(b)

Figura 1 - Arquitetura do sistema. (a) aparelho celular, (b) etiqueta NFC.

Fonte: elaborada pelos autores.

De fácil utilização e simples funcionamento, o NFC entra em ação quando dois dispositivos são aproximados entre si formando um campo magnético que permite a troca de dados através de um espectro de alta frequência na portadora de $13.56 \mathrm{MHz}$. Nesta etapa a fonte de energia é gerada por apenas um aparelho, onde este age ativamente, desta forma é possível que o smartphone sem o contato físico acesse os dados de uma memória não volátil de uma etiqueta ou de outro dispositivo qualquer, desde que este seja compatível. Desta forma o celular recebe as informações da etiqueta e transmite em forma audível para o usuário. Para uma descrição técnica completa do sistema em NFC consulte ISIDRO (2014). 


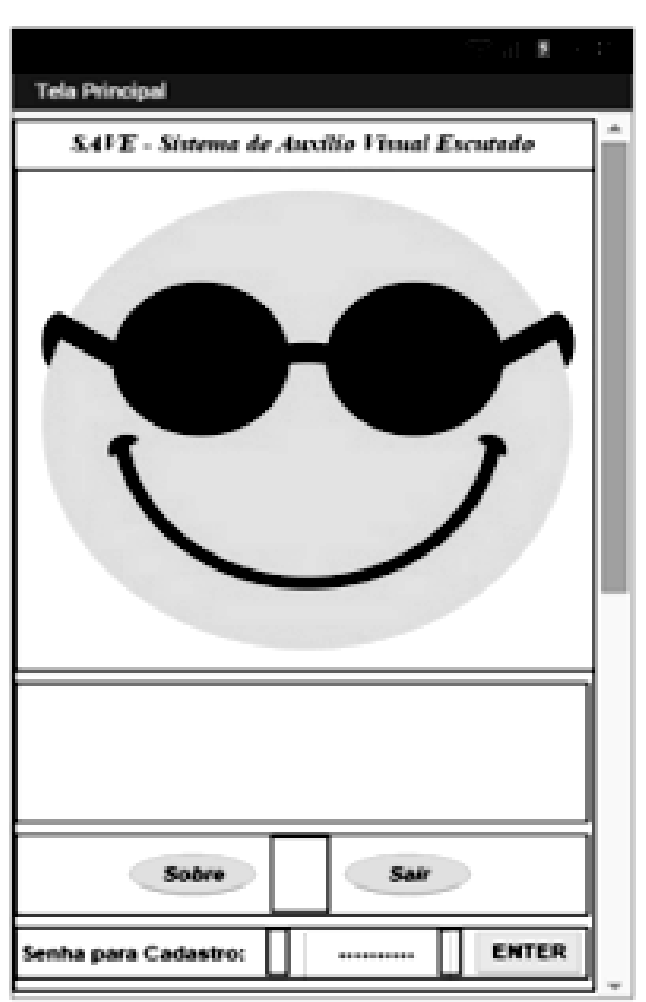

(a)

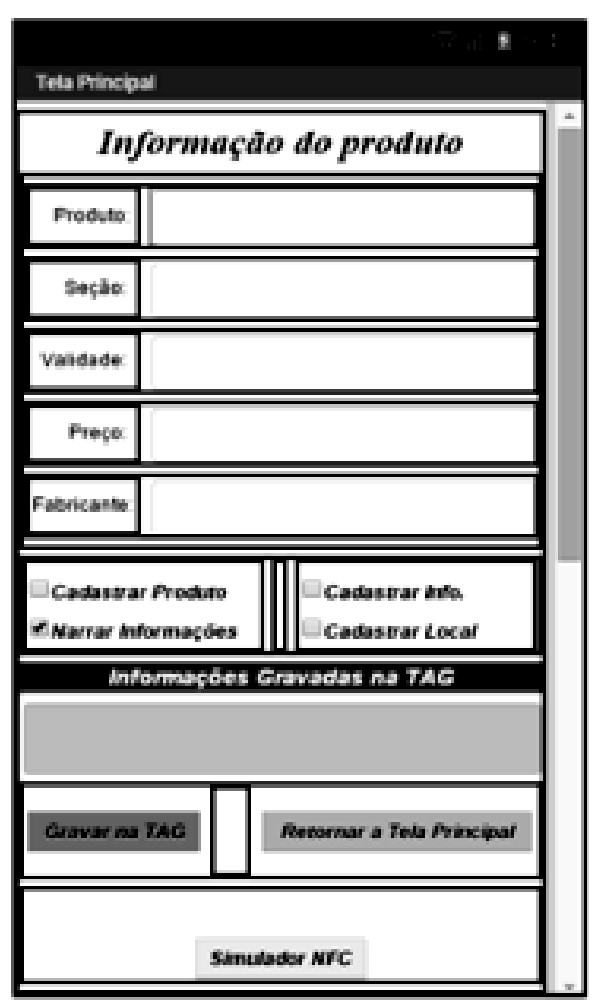

(b)

Figura 2 - (a) Interface do usuário; (b) Interface do administrador. Fonte: elaborada pelos autores.

Para que as tarefas fossem realizadas pelos deficientes, foi necessário criar uma interface entre o usuário e o produto, responsável por decifrar e converter em áudio as informações dos produtos bem como servir de interface para o administrador do estabelecimento carregar as informações dos produtos. Desenvolvido com o App Inventor o SAVE visa facilitar a interação entre usuário e o aplicativo através de uma tela principal (Figura 2a) que conta com funções básicas, como botões de saída e informação do desenvolvedor, bem como o local para castrado de produtos (usado apenas pelo administrador), botão "ENTER" (iniciar) e uma imagem sensível ao toque que é responsável por liberar o comando de voz.

Como os dados dos produtos são armazenados dentro do aplicativo criou-se uma interface (Figura 2b) para que o proprietário do estabelecimento (administrador) fizesse a entrada das informações nas etiquetas, utilizando seu smartphone, onde somente este terá acesso (através de uma senha) ao cadastro e demais informações pertinentes ao seu produto. O processo de gravação é muito simples e prático, necessitando apenas da senha para liberação do cadastro das informações desejadas. Para tal, quando for necessária qualquer entrada, alteração ou remoção de dados, basta acessar a janela de informação do produto, alterar os dados, clicar no botão verde gravar na etiqueta, aproximar a etiqueta do smartphone e aguardar a confirmação áudio visual de sucesso na gravação. 
Sistema de apoio à localização para deficientes visuais

Através das etiquetas passivas, que possuem informações referentes a um produto qualquer, é possível se comunicar através de uma frequência de 13,56 MHz, onde para cada título cadastrado em sua memória há um código que será convertido na informação do produto, ou até mesmo em informação a ser gravada diretamente na mesma, conforme mostra o diagrama de blocos lógico do sistema desenvolvido (Figura 3). Com o celular atuando como um meio ativo nesta aplicação, seu sinal de transmissão é maior do que o da etiqueta, portanto ao incitá-la as informações são coletadas pelo smartphone e transferidas diretamente para o aplicativo, que as decodifica e disponibiliza na tela do seu celular, enviando o texto para narração de forma temporal. Para inserção de dados na etiqueta, basta realizar o caminho inverso. Uma vez que os dados são inseridos no aplicativo, as informações são decodificadas e enviadas à etiqueta quando o botão de gravar é acionado.

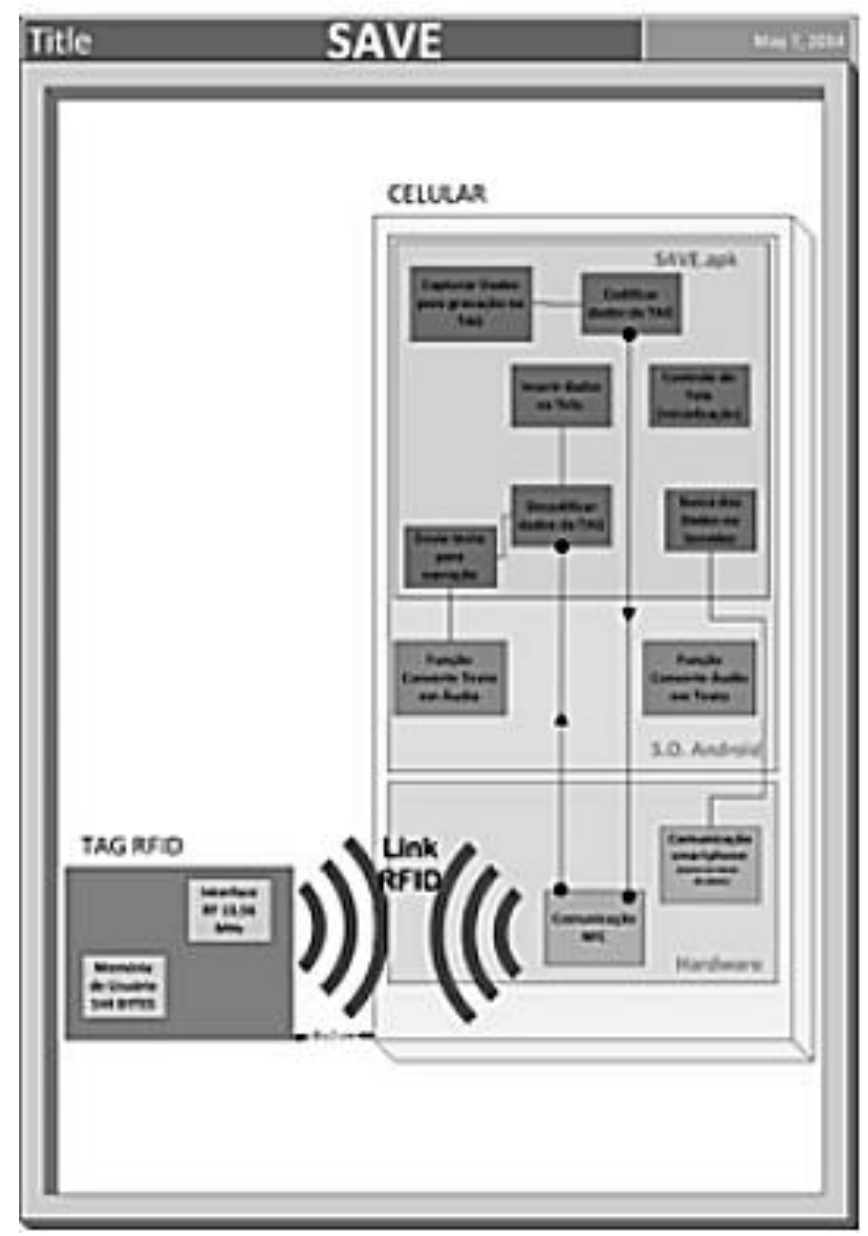

Figura 3 -Diagrama de blocos lógico do sistema. Fonte: elaborada pelos autores. 


\section{Modelo de Desenvolvimento}

O Modelo de Desenvolvimento de Soluções é dividido em quatro fases: 1) Entendimento: fase inicial onde o objeto a ser desenvolvido é dialogado com os técnicos da instituição parceira visando obter concordância com relação à arquitetura e planejamento do projeto. 2) Elaboração: Esta é uma fase onde as informações obtidas na fase anterior são sistematizadas e transformadas em funcionalidades e especificações do projeto. Neste momento a arquitetura da solução ou artefato é validada. 3) Construção: Nesta fase, fortemente interna ao projeto, o artefato elaborado é construído dentro das especiações obtidas na fase de concepção, sempre validando com o público alvo. 4) Transferência: Aqui onde os técnicos da instituição são treinados em como montar o artefato desenvolvido e se apropriam da solução.

\section{Modelo de Apropriação de Resultados}

O Modelo de Apropriação de Resultados segue os seguintes passos: 1) Captura; 2) Desenvolvimento; 3) Validação; 4) Demonstração; 5) Treinamento; 6) Verificação /Transferência; e 7) devolutiva a ser descrita em outra publicação. O ciclo de construção coletiva de conhecimentos realizado através de trocas de experiências, conversas e discussão é apresentado na Figura 4.

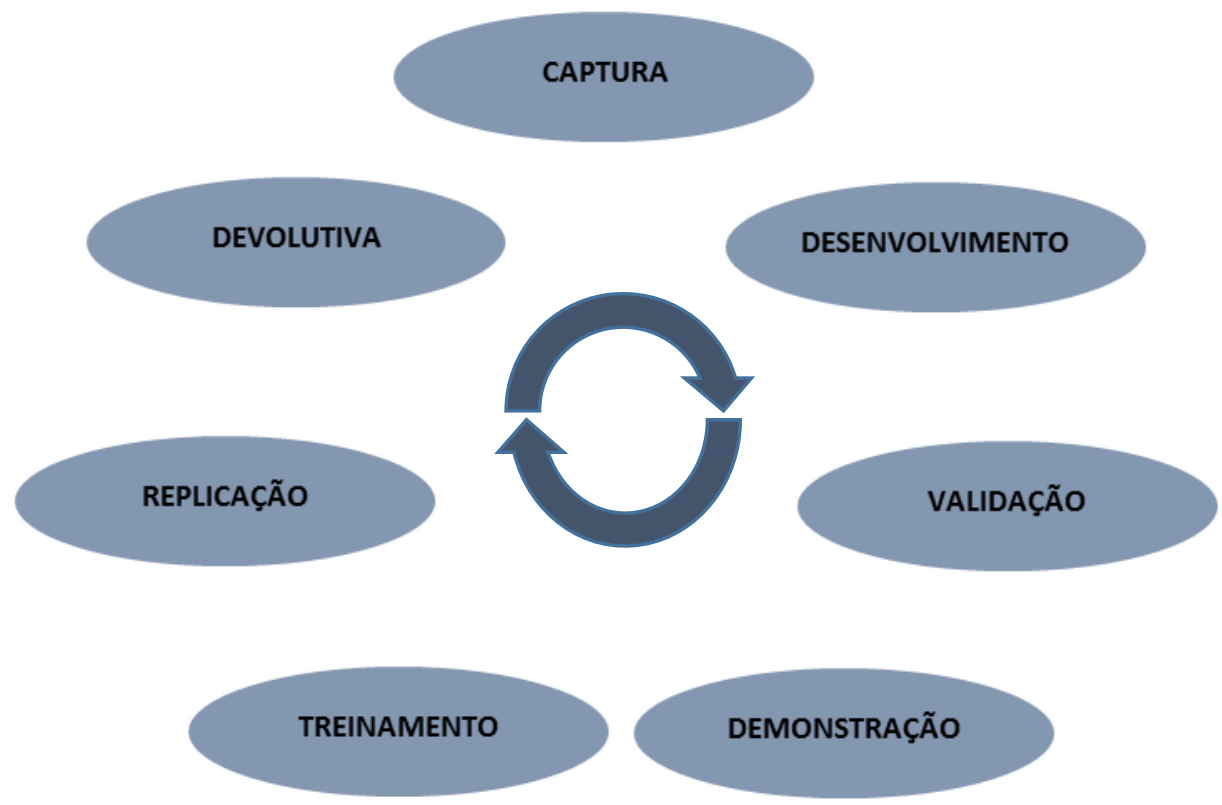

Figura 4 - Modelo de Apropriação de Resultados. Fonte: elaborada pelos autores. 
Sistema de apoio à localização para deficientes visuais

\section{RESULTADOS E DISCUSSÃO}

O sistema desenvolvido foi testado para verificar a conformidade aos requisitos apontados pelos técnicos da instituição parceira e os deficientes visuais. A Figura 5, abaixo mostra a bancada de testes para validação da sensibilidade e configuração técnica do sistema. As medidas expostas na Figura 6 são resultantes da medição do range de comunicação entre etiqueta e smartphone.

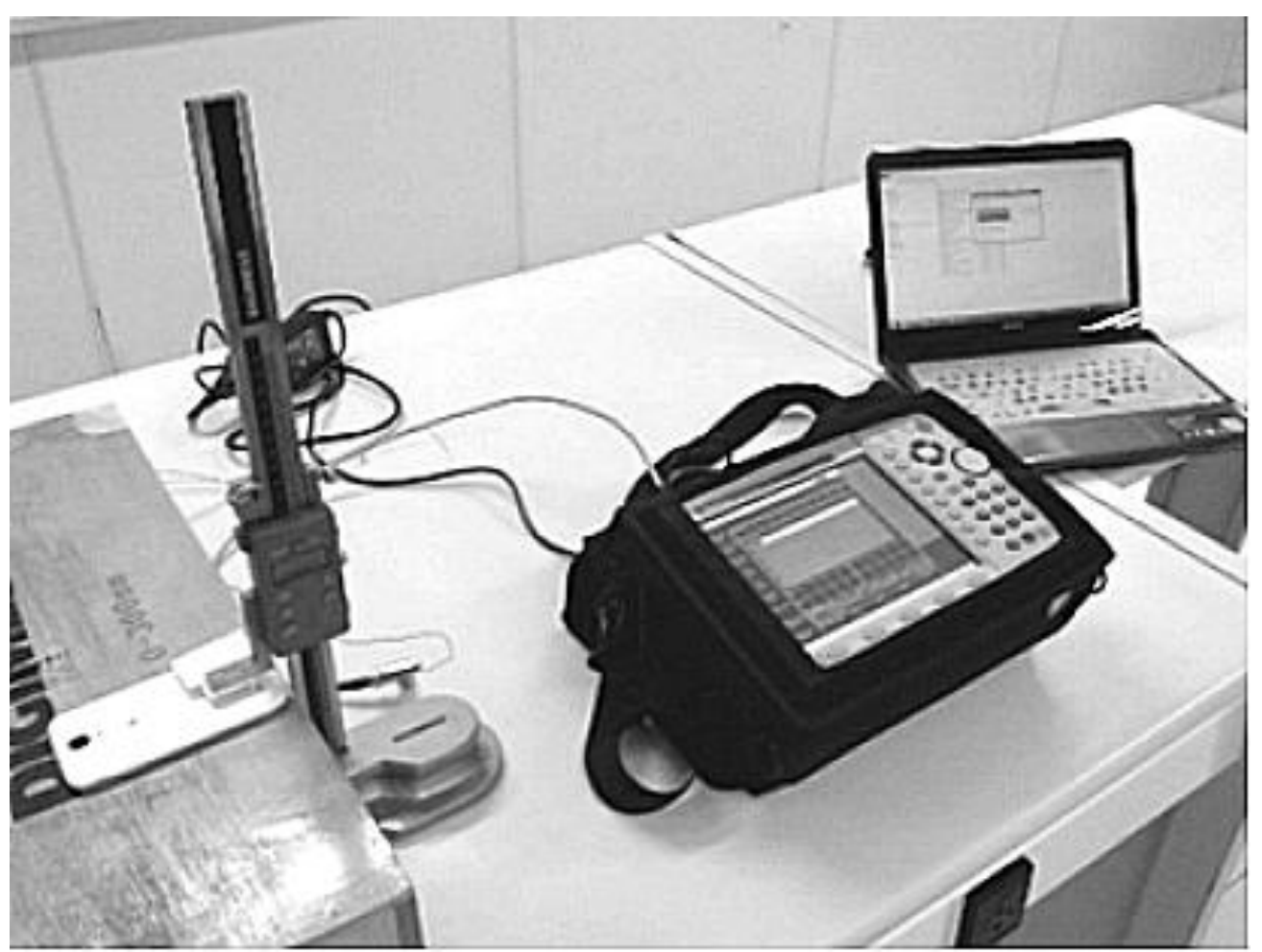

Figura 5 - Estrutura montada para medir o alcance do sinal. Fonte: elaborada pelos autores. 


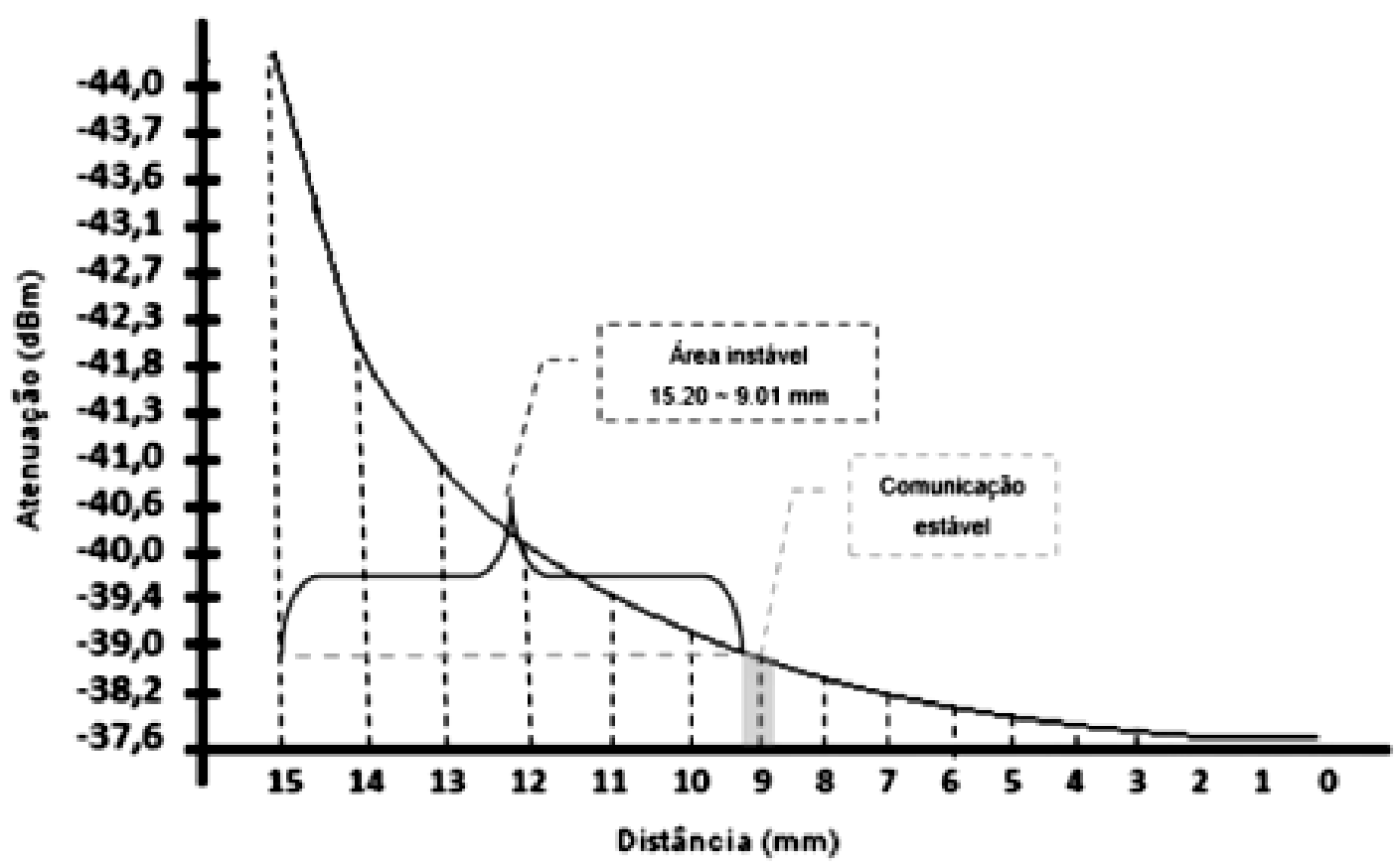

Figura 6 - Alcance de comunicação entre etiqueta e smartphone. Fonte: elaborada pelos autores.

O ensaio realizado para a detecção do das etiquetas foi pela técnica de aproximação, a etiqueta foi afastada do smartphone em $20,00 \mathrm{~mm}$ a qual foi sendo aproximada milímetro por milímetro do periférico ativo. Foi constatada detecção a partir de $15,20 \mathrm{~mm}$, porém sem que o enlace de comunicação fosse realizado. Segundo a Figura 6 nota-se que entre 15,20 e 9,01 mm há uma zona de instabilidade que não gera enlace suficiente para que a informação contida na etiqueta seja transmitida ao smartphone. Somente a partir de 9,01 mm que intensidade do sinal se tornou estável provendo o compartilhamento das informações entre dispositivos. É importante ressaltar que a atenuação do sinal está diretamente ligada à distância nota-se que enquanto a intensidade do sinal é de $-37,6 \mathrm{dBm}$ para $0,00 \mathrm{~mm}$ para 15,20 $\mathrm{mm}$ é de $-44,00 \mathrm{dBm}$.

Uma vez que os testes foram satisfatórios, foi realizada uma demonstração do SAVE simulando o uso numa mercearia. Com a parceria entre PUC-Campinas e Instituto Campineiro de Atendimento ao Deficiente Visual Pró-Visão, foi possível realizar uma demonstração do aplicativo em funcionamento. A Figura 7 apresenta a validação do sistema por um deficiente visual. A demonstração do sistema numa oficina de demonstração de resultados permitiu validar a aceitação junto aos deficientes visuais, quando $80 \%$ deles manifestaram-se positivamente quando questionados se a solução tem potencial para promover a autonomia e a independência. 




Figura 7 - Validação do sistema SAVE por um deficiente visual. Fonte: elaborada pelos autores.

Um resumo dos resultados das entrevistas conduzidas com os assistidos pela Pró-Visão é apresentado na Figura 8.

Ainda que os deficientes visuais participantes do projeto não tiveram contato antecipado com a prova de conceito, observa-se que eles entendem que esta usa um dispositivo de comunicação adequado, é de fácil utilização e bastante útil para a superação das tarefas diárias que envolvam a localização de objetos ou itens. 

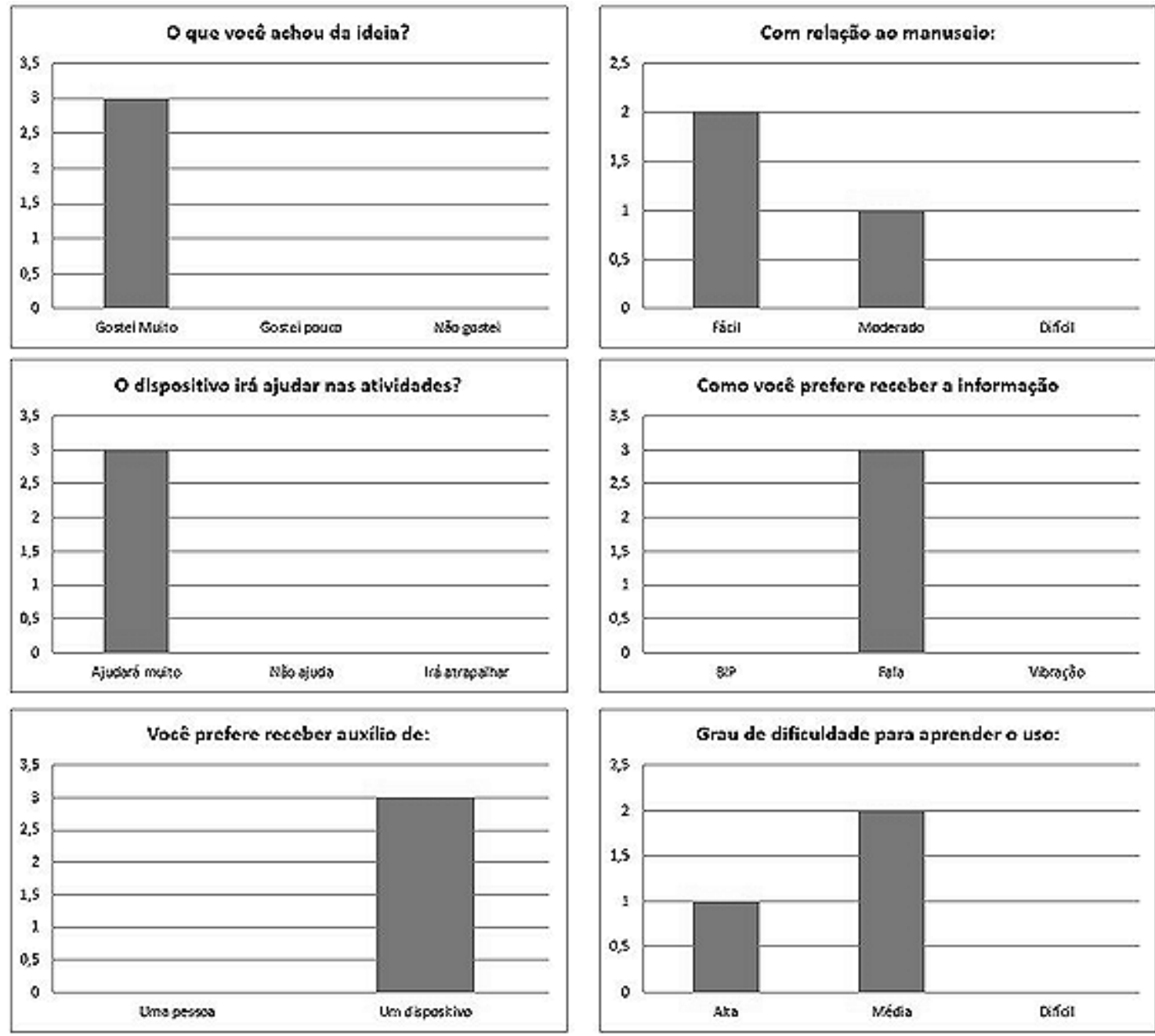

Figura 8 - Resumo das respostas aos questionários.

Solução desenvolvida e validada - transferência em andamento - artefatos de E.E. contribuem para a melhoria da qualidade de vida. Finalmente validou-se, preliminarmente, a prova de conceito em Oficina de Demonstração quando os assistidos e suas famílias experimentaram o aplicativo. Nesta oficina foi montado um ambiente que simula um mercado de alimentos e os assistidos exercitaram com sucesso a localização e identificação das características de produtos de interesse. Simultaneamente aplicaram-se questionários de opinião onde os assistidos foram unânimes em reconhecer que a solução ajuda na realização das tarefas propostas bem como a maioria entendeu que a solução é de uso fácil. Desta forma conclui-se que soluções de Engenharia Elétrica baseadas em NFC podem contribuir para a autonomia de deficientes visuais. Desenvolvida prova de conceito baseada em conceitos de Engenharia Elétrica que estimula o desenvolvimento sensorial de deficientes visuais contribuindo para a promoção da 
Sistema de apoio à localização para deficientes visuais

autonomia e cidadania. A prova de conceito segue as especificações de técnicos especializados no atendimento de deficientes visuais.

\section{AGRADECIMENTOS}

Agradecemos a Pró-Visão, Sociedade Campinas de Atendimento ao Deficiente Visual. Um dos autores (Amilton Lamas) gostaria de agradecer a Pró Reitoria de Extensão e Assuntos Comunitários da PUC-Campinas pelo apoio ao projeto.

\section{REFERÊNCIAS}

BRASSAI, Sándor Tihamér et al, Assistive Technologies for Visually Impaired People, Acta Universitatis Sapientiae, Electrical and Mechanical Engineering, 3 (2011) 39-50.

FUNDAÇÃO INSTITUTO BRASILEIRO DE GEOGRAFIA E ESTATÍSTICA. Censo Demográfico 2010, Resultados Gerais da Amostra, Rio de Janeiro, 2010.

ISIDRO, Rafael, Sistema de auxílio visual escutado, trabalho de conclusão de curso, Faculdade de Engenharia Elétrica, PUC- Campinas, 2014.

LÉVESQUE, Vincent, Blindness, Technology and Haptics, Centre for Intelligent Machines, McGill University, Montreal, Québec, Canada, 2011.

TORRE, G. Robles-De-La-, Virtual Reality: Touch / Haptics em Goldstein B. (Ed.) encyclopedia of Perception, Vol.2, pp. 1036-1038. Sage Publications, Thousand Oaks, CA, 2009.

VELÁZQUEZ, Ramiro, Wearable Assistive Devices for the Blind. Capítulo $17 \mathrm{em}$ LayEkuakille \& S.C. Mukhopadhyay (Eds.), Wereable and Autonomous Biomedical Devices and Systems for Smart Enviromment: Issues and Characterization, LNEE 75, Springer, pp 331 - 349, 2010. 